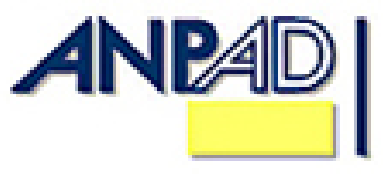
Disponível em
http://www.anpad.org.br/rac
RAC, Rio de Janeiro, v. 18, n. 5,
pp. 695-709, Set./Out. 2014
http://dx.doi.org/10.1590/1982-7849rac20141067
$(\mathrm{cc})$ EY-NO

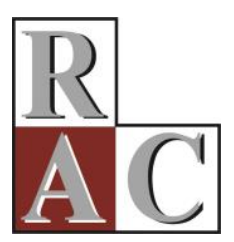

Documentos e Debates:

\title{
Por que Ler os Clássicos no Ensino e na Pesquisa em Administração?
}

\section{Why Read Teaching and Research Classics in Management?}

Francis Kanashiro Meneghetti

E-mail: fkmeneghetti@gmail.com

Universidade Tecnológica Federal do Paraná - UTFPR Av. Sete de Setembro, 3165, PPGTE, sala 5, Rebouças, 80230-901, Curitiba, PR, Brasil.

Edson Ronaldo Guarido Filho

E-mail: edson.guarido@gmail.com

Universidade Positivo - UP

Rua Prof. Pedro Parigot de Souza, 5300, Campo Comprido, 81280-330, Curitiba, PR, Brasil.

Ariston Azevêdo

E-mail: aazevedo@ea.ufrgs.br Universidade Federal do Rio Grande do Sul -UFRGS Rua Washington Luiz, 855, Campo Comprido, 90010-460, Porto Alegre, RS, Brasil. 


\title{
Introdução
}

\begin{abstract}
“Apenas comecei a escrever, pousei minha pena para rejubilar-se. A impostura era a mesma, mas eu já disse que tomava as palavras como a quinta-essência das coisas. Nada me perturbava mais do que ver meus garranchos trocando pouco a pouco seu brilho de fogos-fátuos pela pálida consistência da matéria: era a realização do imaginário".
\end{abstract}

(Sartre, 1964, p. 90).

A discussão a que se propõe este ensaio não é das mais fáceis. Além de ser um tema que, para ser discutido, demanda dos autores conhecimentos adquiridos durante trajetórias acadêmicas baseadas nas leituras dos clássicos, exige, na prática docente e na pesquisa de programas de mestrado e doutorado, o hábito de mostrar a importância dos clássicos na formação de pesquisadores que pretendem adquirir uma condição intelectual diferenciada, não se contentando apenas em aprender técnicas de pesquisa.

A relevância dessa discussão da aplicação dos clássicos no ensino e na pesquisa em Administração mostrou-se evidente na apresentação do trabalho de Meneghetti, Guarido e Azevêdo (2012), em que mais de 50 (cinquenta) pessoas participaram de uma sessão interativa discutindo, entre outros temas, a importância dos clássicos.

Opiniões divergentes à parte, verificou-se que esse tema precisa ser discutido e debatido, e não apenas apresentado para a comunidade científica, uma vez que essa discussão vem ao encontro de reflexões mais profundas, como: (a) a forma de se incentivar a produção do conhecimento, hoje, centrada na produção de papers; (b) o descaso em relação às grandes narrativas, como meio para formação intelectual integral; (c) a adesão às formas rápidas de aquisição de conhecimentos, baseados mais em informações estruturadas do que em reflexões profundas sobre a realidade; (d) o descarte do que é considerado velho, por acreditar que ele não pode ajudar a compreender a realidade de hoje.

Apesar disso, obras como A República de Platão, Política de Aristóteles, Confissões de Santo Agostinho, O Capital de Karl Marx ou A Ética Protestante e o Espírito do Capitalismo de Max Weber são frequentemente consideradas clássicos, exemplares cujo consenso a seu respeito é tamanho, que raros intelectuais seriam capazes de afirmar o contrário. Como escreveu Adorno (1993, p. 75), "são como teias de aranha: densos, concêntricos, transparentes, bem estruturados e sólidos", e que, na ótica de Benjamin (1991), permitem aos leitores, tanto como aos autores, serem produtores de reflexões originais.

Estas são apenas algumas das características atribuídas aos clássicos e que expressam sua transcendência para além do tempo histórico da obra e das características do leitor de uma determinada época. Tal primazia agrega ao clássico um caráter de ente permanente na formulação do pensamento e na construção do conhecimento que, mesmo sob interferência de transformações históricas, faz-se presente como referência nas diversas épocas e para diversos públicos.

É, pois, nessa lógica da transcendência dos clássicos, que o presente trabalho está orientado com objetivo, antes de tudo, ensaístico num sentido amplo, dessa maneira, buscando suscitar questões sobre a formação, difusão e aceitação de determinados cânones sobre os quais o conhecimento é, em grande medida, realizado e estruturado. Discutir a importância dos clássicos na Administração ${ }^{(1)}$, nesse sentido, não implica elaborar um conceito sobre o que seja um clássico, nem atribuir imperativos para tal definição, muito menos enumerar obras ou autores clássicos, ou estabelecer parâmetros para sua categorização como tal. Ao contrário, significa, com base em seus traços peculiares, refletir acerca de sua natureza, de tal modo que sua apreensão como fenômeno objetivo é aqui concebida como decorrente de processos sociais inerentes à construção do conhecimento.

Com isso em vista, o presente ensaio teórico está dividido em cinco seções, além desta introdução. Na primeira delas são tratados alguns dos atributos normalmente associados aos clássicos, tendo-se como referência a pergunta crítica: o que é um clássico? Ou, sob outro olhar: é possível definir um 
clássico? Para tanto, recuperam-se as diferentes acepções expostas por Calvino (1993), conjugando os aspectos por ele indicados a outros pontos amparados no pensamento de diferentes intelectuais modernos.

Nesse ínterim, uma questão contraditória emerge como pano de fundo para o debate subsequente: as mesmas tentativas de caracterização dos clássicos, que visam extrapolar noções vulgares do senso comum, remetem a racionalizações que admitem tacitamente uma grande amplitude de qualificações a eles atribuídas, cuja imprecisão os coloca como categoria taken for granted. Por conseguinte, tem-se que clássico pode ser entendido, de forma rudimentar, como categoria (ou gênero) associada aos segmentos da literatura, como, por exemplo, os clássicos da sociologia, ou a literatura clássica brasileira. Além disso, pode representar uma qualidade de um autor ou sua obra, no sentido de: Parsons é um clássico da Sociologia americana, ou O Suicídio, de Durkheim, é um clássico da Sociologia.

Em todos os casos, apesar de expressarem diferentes objetos de referência, concernem-se, sobretudo, a representações historicamente situadas e compartilhadas do conhecimento. Decorre, daí, o reconhecimento de que há um componente interpretativo ligado à construção social daquilo que é admitido como clássico, o que implica refletir no tocante a seu contexto e validade, ou, em termos gerais, sua historicidade e legitimidade, pontos tratados, respectivamente, nas segunda e terceira sessões subsequentes.

Em seguida, na quarta seção, reflete-se, à luz do discutido, a respeito das razões que conduzem à leitura dos clássicos, tendo em vista seu papel potencial na formação de um campo de conhecimento. Neste ponto, fazem-se também reflexões sobre a presença essencial de clássicos nas Ciências Sociais, as quais estão associadas a sistemas supracientíficos de natureza cultural e intelectual que alicerçam o discurso, de modo que sua interpretação é inerente à própria prática científica.

Encerra-se este ensaio com a retomada das conexões entre os pontos tratados ao longo do texto, contudo sem a pretensão de estabelecer conclusões, mas, principalmente, para constituir um conjunto de indagações finais que remetem o porquê de ler os clássicos na Administração à sua inserção social no sistema de construção do conhecimento científico.

\section{Por uma definição de clássico}

Por ser aplicável aos diversos meios ligados às expressões do conhecimento oriundas das artes, da literatura, da música e das ciências, o adjetivo clássico, atribuído a uma obra ou autor, possibilita pensar em diferentes acepções que o justificariam e que, por consequência, apontariam para uma variedade de aspectos definidores. Uma razão para isso se deve ao fato de que a qualidade de clássico é usualmente tomada como taken for granted, sendo poucas vezes questionada, de tal modo que é incomum encontrar significações ou descrições precisas sobre suas propriedades (Porter, 2005), permitindo reportar-se ao primeiro questionamento deste ensaio: é possível definir um clássico? Essa questão, tomada como ponto de partida, suscita algumas excursões nos elementos que possam qualificar os clássicos, os quais serão aqui pautados, em grande medida, em reflexões feitas por Ítalo Calvino ${ }^{(2)}$ (1993) em sua obra Por que Ler os Clássicos.

De acordo com Calvino (1993), não é possível ler um clássico sem se perder em reflexões a cada frase ou conjunto de ideias, pois essa leitura exige que o leitor vá além do aparente, da compreensão literal das frases. O clássico, explica, difere de outras obras exatamente porque tem algo de diferente, de original, de imprevisível para o leitor e, por isso, de uma forma geral, "são livros que, quanto mais pensamos conhecer por ouvir dizer, quando são lidos de fato mais se revelam novos, inesperados, inéditos" (Calvino, 1993, p. 12).

Sob tal acepção, clássicos representam um convite à reflexão ou, num sentido bastante específico, ao pensamento autônomo quanto à sua interpretação. Assim, mesmo aceitando-se que promovam a objetivação da realidade, por meio da instituição ${ }^{(3)}$ de uma razão compartilhada no modo de pensar dos indivíduos, em um primeiro momento, seu conteúdo seria capaz de extrair de cada leitor ponderações próprias e independentes. Por consequência, o imaginário compartilhado por um grupo de indivíduos 
decorrente de um clássico adviria da síntese de reflexões particulares, próprias do estímulo do pensamento autônomo, e que, em outras palavras, implica no reconhecimento do gérmen da contradição: apesar do imaginário compartilhado, ele seria capaz de promover certo desconforto e questionamento quanto às razões ou percurso que conduzirem ao seu sentido comum.

Razão para tanto pode decorrer do fato de aos clássicos ser atribuído caráter universalizante, no sentido de não ficarem restritos a fronteiras específicas de conhecimento, submetidas à corrupção de suas concepções sob o jugo de interesses seccionais. Diferentemente, eles, em geral, são apreciados por indivíduos ou grupos com perspectivas opostas de ideias e, por isso, não estão subordinados à tradição, podendo até subvertê-la, ao desenvolver-se por meio de uma dialética negativa, segundo a concepção de Adorno (2009). Deste modo, podem ser interpretados como expressão da unidade dos contrários, da existência de uma universalidade possível sem que se caia no equívoco do estabelecimento de uma verdade específica. Eles são, segundo Schopenhauer (2009, p. 46), formadores de "pensador[es] de força[s] própria[s]".

Essa multiplicidade de interpretações, retornando a Calvino (1993, p. 12), faz do clássico "uma obra que provoca incessantemente uma nuvem de discursos críticos sobre si, mas continuamente as repele para longe". Contudo não se pode negar que, da mesma forma que empoderam os leitores por meio da possibilidade de estimular o pensamento próprio e do despertar de sentimentos ambivalentes, podem, por vezes, ser objeto de apropriação ideológica de seu conteúdo. Nessas circunstâncias, o uso dogmático de obras literárias, filosóficas, sociológicas, etc., caracterizadas como clássicos, tende a esvair o caráter emancipatório inerente ao seu conteúdo, expressando, contraditoriamente, tentativas de alienação decorrentes de interpretações ideológicas de caráter fundamentalista e, por vezes, oportunista, em favor da imposição de interesses particulares ou seccionais. Exemplos desse fenômeno foram o uso das ideias de Marx e Nietzsche como instrumento de dominação ideológica por indivíduos dotados de uma verdade dogmática. Enquanto o primeiro teve sua obra disseminada pelos ditos socialistas da exUnião das Repúblicas Socialistas Soviéticas, o segundo foi acusado de ser um filósofo que ajudou a construir o pensamento nazista. Em situações como essas, evidentemente, não se pode responsabilizar seu conteúdo pelos equívocos e insanidades realizadas por terceiros que, em favor de uma ideologia, apropriaram-se convenientemente de suas ideias para agir de forma reacionária e violenta; é como culpar o Alcorão pela morte de vítimas inocentes de ataques terroristas.

Entretanto, paradoxalmente, o caráter conformador dos clássicos perde valor ante sua característica de revisitar pressupostos tidos como verdades, uma vez que apresentam, frequentemente, a condição imanente de confrontá-los recorrentemente com as teses do leitor. Tal propriedade tem relação com o destaque apontado por Calvino (1993), quanto ao fato de os clássicos apresentarem-se como uma riqueza para quem os leem repetidamente e pela primeira vez. De acordo com o autor, "clássicos são aqueles livros dos quais, em geral, ouve-se dizer: 'Estou relendo"” (Calvino, 1993, p. 10). Isso porque o leitor raramente encontra certezas no decorrer da leitura, pois suas inquietações iniciais são substituídas por outras, de tal modo que, a cada novo contato com o conteúdo, o leitor se depara com constantes intervalos de reflexão. Entre frases, parágrafos, argumentações e ideias, tal indução para a reflexão garante movimento nas análises da realidade. É o próprio vir a ser que se torna síntese.

Contudo muitos leitores recorrem aos clássicos quando necessitam pensar em terrenos sólidos. Obras clássicas, neste sentido, deixam de ser pontos de partida e passam a ser, por um lado, fundamentos racionais para sistematizar o pensamento e, por outro, apoios irracionais que servem para acalmar consciências inquietas que buscam corroborações de suas angústias.

Sob essa acepção alternativa, Calvino (1993) afirma que o clássico é uma obra "que se configura como equivalente do universo, à semelhança dos antigos talismãs" (p. 13). Os clássicos procuram explicar algo por meio de uma totalidade, ou seja, constituem-se como tentativa de compreensão de um objeto dentro de um todo relacionado a ele. Este poderia ser o caso de Marx, quando procurou entender o capital; de Weber, em relação ao espírito do capitalismo; ou de Aristóteles, quanto ao conhecimento das causas iniciais no livro Metafísica. 
Mas a riqueza dos clássicos também se faz na medida em que sua leitura desperta, no leitor, a sensação de que já tomou contato com seu conteúdo em outro momento. Esta sensação não necessariamente se apresenta de modo consciente e está relacionada a dissonâncias entre possíveis lembranças e a sensação de impotência ante o novo do texto incompreendido na sua totalidade diante da dificuldade em contextualizar o possível contato passado. "Dissonância que os posiciona como digressões da razão e do imaginário, muitas delas pertencentes ao inconsciente social" (Fromm, 1992, p. 22). Eles se confundem com a história das mudanças sociais, com leituras de obras passadas, com imaginários sociais instituídos e, por isso, ao passo que suas contribuições estão nos conteúdos que organizam racionalmente, constituem, eles próprios, elementos necessários para estabelecer inteligibilidade na compreensão da realidade.

Calvino (1993) expressa essa conexão entre presente e passado definindo clássicos como obras "que chegam até nós trazendo consigo as marcas das leituras que precederam a nossa e atrás de si os traços que deixaram na cultura ou nas culturas que atravessaram (ou mais simplesmente na linguagem ou nos costumes)" (p. 11). Nesse sentido, são construídos no tempo, por meio de interpretações condicionadas pelo contexto em que se apresentam e, portanto, não pertencendo especificamente a alguém. Por quaisquer que sejam os interesses compreendidos em sua exploração comercial ou intelectual, eles são evidência de que o conhecimento extrapola sistemas econômicos e sua propriedade se consolida, meramente, pela condição de o seu conteúdo pertencer à humanidade.

Questões como essas remetem a outro aspecto que faz relação com propriedades eventualmente ligadas aos clássicos: sua utilidade. Normalmente, não se atribui a eles papel específico no processo de ensino-aprendizagem nos moldes dos livros didáticos. Também não se caracterizam como elemento pragmático de construção do conhecimento, apesar de possibilitarem a produção do saber pela autonomização da consciência. Além disso, como já mencionado, sobrepassam interesses específicos do mercado editorial, como as exigências ligadas aos requisitos de linguagem, da estruturação do texto ou do respeito a regras formais. Tais formalismos configuram-se secundários frente à liberdade intelectual estimulada no leitor e também não são centrais na qualificação de obras como clássicas, cuja força está no conjunto das suas ideias e no impacto gerado na audiência, entendido como conhecimento, ao longo do tempo.

Assim, pode-se admitir que clássicos estejam associados a elementos não formais, o que remete a aspectos de natureza afetiva, ideológica, contextuais e sociais.

Afetiva porque eles despertam paixões, instigando o aparecimento de sentimentos ambivalentes no escritor e no leitor, sejam eles de idolatria, repulsão, admiração, ou de qualquer outra natureza, mas raramente de indiferença. Nesse sentido, a posição ativa dos leitores na compreensão do clássico revela modos de entendimento ou de elucidação de conhecimento nos quais estão imersos. Por consequência, como já discutido, tal atitude sobre clássicos pode, por um lado, ser convertida em promoção dogmática de ideias, mas, por outro, sob a ótica da independência intelectual do leitor, pode ser inspiradora de nova interpretação da realidade em favor de compreensões menos mecanicistas, pragmáticas ou predeterminadas. Assim, pressupostos podem ser questionados, conceitos requalificados e concepções reavaliadas, tanto no âmbito coletivo como no individual, de modo que se pode admitir certo componente subversivo nos clássicos, na medida em que provocam a ampliação da esfera pública como centro de discussão (Arendt, 2003) e o posicionamento do leitor para além da condição de expectador ou consumidor de ideias preconcebidas, coibindo o que Horkheimer (2000) definiu como eclipse da razão. Sob essa ótica, clássicos sintetizam potenciais compreensões da realidade, decorrentes da conjugação das trajetórias analíticas e temporais perseguidas por autor e leitor.

Contudo a relação de clássicos com o seu contexto histórico nem sempre é harmônica, provocando estranhamentos ou resistências sociais, justificadas, por vezes, pela consideração de sua dissonância provável com o pensamento tradicional. Isto pode ser exemplificado historicamente com as obras de Sócrates, na Grécia Antiga, ao ser acusado de subverter a juventude; de Santo Agostinho, por ter enfrentado resistências a suas obras em uma época de conservadorismo cristão e de Marx, por questionar os pressupostos do capitalismo. 
Essa condição explicativa da realidade e por sua capacidade de fomentar ideias, imaginários e sistemas racionais capazes de estruturar uma visão de mundo, também, habilitam associar aos clássicos um componente ideológico. Mesmo que toda a obra tenha algum posicionamento político e moral, não se deve atribuir ao autor as interpretações possíveis que um coletivo possa realizar, de tal modo que seu potencial inerente de provocar uma multiplicidade de interpretações pode incentivar conflitos de perspectivas e situações de competição na forma de conflitos ideológicos e intelectuais. Todavia, apesar de resistências e até mesmo de boicotes, os clássicos acabam por apresentar força interna própria, representada pela concepção compartilhada de sua importância para além dos limites contextuais em que foram originalmente produzidos.

Tudo isso indica que os clássicos estão associados à compreensão do processo civilizatório por dependerem de quem escreve, mas, sobretudo, do leitor. A obra, como algo que existe em si mesmo, resulta de um movimento dialético e reflexivo, em que o pensamento do escritor, a realidade que o inspirou na produção da obra e o pensamento do leitor estão imbricados. Nesse ponto, o pensamento cartesiano de um indivíduo com consciência autônoma (Descartes, 1973) parece conveniente, pois leva a uma condição subjacente ao clássico e sua relação com a independência intelectual. Contudo seu significado precisa estar desassociado da atribuição de poderes extraordinários ao indivíduo isolado, reconhecendo que a autonomia do indivíduo se efetiva porque ele está inserido em uma rede de relações sociais mais amplas, que atua tanto nas determinações materiais como nas interpretações possíveis da interação com o mundo. A reflexão, apesar de parecer um ato isolado e solitário, é pautada pela historicidade e inserção dos indivíduos em um contexto social. Desse modo, diferentes condicionamentos históricos influenciam as formas de organização social e, por decorrência, a estruturação do conhecimento, do qual os clássicos são definidos. Calvino (1993) sintetiza esse ponto afirmando que eles "exercem uma influência particular quando se impõem como inesquecíveis e também quando se ocultam nas dobras da memória, mimetizando-se como inconsciente coletivo ou individual" (pp. 10-11).

Diante do até aqui discutido, é possível finalizar esta seção retomando algo já mencionado: clássicos remetem a características que, de um modo ou outro, possibilitam várias definições. No entanto a presente proposta de discussão a respeito não se refere propriamente aos seus atributos, sejam eles formais ou da estrutura lógica de exposição, defendidos por um ou outro autor. Diferentemente, trata-se da consideração do fato de que não há propriedades clássicas intrínsecas ao objeto, de tal modo que "a ideia de clássico é um ideal que é no máximo sugerido, mas não confirmado, pelos objetos concretos" (Porter, 2005, p. 30). Ao mesmo tempo, não se está atribuindo a qualidade clássica a artefatos de um tempo na história, ou ainda àquelas obras que expressam determinados valores considerados clássicos. $\mathrm{Na}$ realidade, a atribuição do caráter clássico apresenta sujeitos individuais e coletivos, de tal modo que a consideração das propriedades tidas como intrínsecas aos clássicos, mais do que imperativos universais, representa critérios estabelecidos por uma audiência ao longo do tempo. Desse modo, parece apropriado, neste momento, refletir sobre a construção social do clássico.

\section{Construção social do clássico}

Os atributos dos clássicos representam propriedades ilusórias dos objetos, de modo que não há predicados clássicos que possam estar em posse do objeto, sejam eles uma peça da literatura ou uma obra científica. O que se tem é uma construção imaginária. A atemporalidade, no sentido de características inequivocamente intrínsecas, frequentemente, atribuídas aos clássicos, é, na realidade, expressão de valores universalistas, de preferências socialmente construídas e que atribuem a aparência de clássico a uma obra definitiva. Por esse raciocínio, a presente reflexão trata da definição do que é clássico enquanto experiência intersubjetiva construída historicamente e que fomenta significado e essência, contextualizados no tempo e no espaço, sem a preocupação com a identificação de atributos objetivos de uma obra em particular. Como explica Porter (2005, p. 54), "o clássico nunca é diretamente apreendido: ele sempre vem indiretamente e de segunda mão, o que significa dizer que é a transferência, não meramente da percepção, mas de uma ilusão, ou fantasia, sobre o passado". Logo, são produtos sociais; a atenção repousa não sobre o objeto, mas em sua representação compartilhada dentro de um imaginário instituído. 
Calvino (1993, p. 11) expressa bem esse ponto ao afirmar que "um clássico é um livro que nunca terminou de dizer aquilo que tinha para dizer", ou, numa formulação mais explicativa, clássicos "são aqueles livros que chegam até nós trazendo consigo as marcas das leituras que precederam a nossa e atrás de si os traços que deixaram na cultura ou nas culturas que atravessaram (ou mais simplesmente na linguagem ou nos costumes)" (p. 11).

Para compreender melhor essa questão, recupera-se a noção de dupla hermenêutica, conforme tratada por Giddens (1978). Como cientistas sociais, utilizam-se conceitos para explicar outros conceitos, ao passo que o conhecimento social em nenhuma circunstância se dá de maneira independente do mundo social. Naturalmente, o movimento contrário também ocorre, por meio do qual, ideias, conceitos e explicações influenciam na concepção e entendimento do mundo social, transformando-o ao longo desse processo (Giddens, 1978; Ritzer \& Smart, 2003). As implicações são várias quando se procura compreender o clássico como objeto valorizado em contextos histórico-culturais, cujos critérios para sua representação são também, eles próprios, construções contextualizadas.

A impropriedade de justificar o caráter clássico por meio de traços do objeto per se remete a processos sociais e isso não significa relativismo radical. A contextualização dos processos sociais, pois, implica tratar de questões ligadas à legitimação e formação de quadros de referências sociais que asseveram a qualidade clássica; embora condicionada socialmente, também, é experimentada individualmente pelo pesquisador ao deparar-se com obras que lhe chamem a atenção. Trata-se, portanto, da instituição da categoria clássica como referência para tipificação do conhecimento expresso nas ciências, tendo em vista parâmetros, valores, traços ou, de modo mais amplo, a consciência, mesmo que não articulada, do que se conhece como clássico. Contudo, vistos como símbolos daquilo que é valorizado com distinção pela comunidade científica, clássicos, também, influenciam no próprio processo de construção do conhecimento, seja atuando sobre a definição da linguagem, nos tipos de debates ou nos problemas considerados válidos (Connel, 1997). Sob essa ótica, eles representam quadros de referência compartilhados, os quais são debatidos, interpretados e legitimados, mas também participam como fonte de legitimação dos discursos acadêmicos.

Logo, clássicos repercutem na estrutura intelectual e, portanto, estão fortemente vinculados à constituição de um campo de estudos e de seu cânone (Davis \& Zald, 2008). Seu papel intelectual, como conteúdo pedagógico disseminado, funde-se na sua dimensão simbólica. Connel (1997) explica que a formação do cânone de uma disciplina está relacionada ao processo pelo qual alguns trabalhos gradualmente alcançam reputação e valorização para uma audiência, constituindo-se em fundamentos, cuja interpretação e reinterpretação definem um campo de conhecimento. De acordo com Alexander (1989), isso dá aos clássicos status privilegiado, expresso na deferência tácita que recebem, sem prévia demonstração, bem como no reconhecimento de que se pode aprender tanto com eles quanto com trabalhos contemporâneos - não quaisquer trabalhos, mas os realmente relevantes e diferenciados.

Tratar da construção social do conhecimento no processo de atribuição de situação privilegiada ao clássico perante uma audiência, ou, no caso das ciências, à comunidade científica, não significa afirmar que sua aceitação seja um sinônimo de consenso intelectual. Por serem resultados de fenômenos culturais, sociais e, consequentemente, tanto quanto para as situações de concordância, clássicos, também, constituem "alicerces sobre os quais as discordâncias científicas são promovidas e sustentadas" (Alexander, 1989, p. 38). Nas palavras de Calvino (1993, p. 15), "é clássico aquilo que persiste como rumor mesmo onde predomina a atualidade mais incompatível".

Apesar disso, o cânone de uma disciplina pode ser entendido como "coleção de clássicos sobreviventes" (Davis \& Zald, 2008, p. 639). Desse modo, aquilo que se afirma como clássico constituise quadro de referência válido, cristalizado em função do reconhecimento social do empreendimento intelectual que se expressa em um determinado tempo. Paradoxalmente, como sobreviventes, são consequências da história e decorrentes das relações sociais, podendo ser recriados, reinterpretados, revigorados, ou mesmo abandonados. Há, portanto, de se reconhecer, nesse processo, o condicionamento das circunstâncias históricas, do papel dos atores e das próprias características da audiência em face dos aspectos contextuais em que está imersa, entre outras condições. 


\section{Clássicos e o contexto histórico}

O entendimento dos clássicos como construção social coloca certa perspectiva no exercício de análise. De acordo com os argumentos defendidos ao longo deste ensaio, eles podem ser tratados como decorrências de processos sociais complexos, historicamente, sustentados e, culturalmente, construídos. Desse modo, configuram-se instituições imaginárias do conhecimento, duráveis e legítimas, embora sua perenidade não signifique perpetuidade ou consenso intelectual. Logo, a noção de mudança nos cânones é inerente à reflexão acerca dos clássicos, seja em razão da atitude criativa associada ao conhecimento, desse modo, facilitando releituras, novas sínteses, redescobertas ou interpretações, seja em razão de aspectos ligados às condições do contexto histórico (Ritzer \& Smart, 2003).

Interessa, neste momento, destacar esses últimos, sobre os quais será dada ênfase nesta seção. Alternativamente, quanto ao que foi até aqui tratado, ao invés de focar a instituição do conhecimento finalizado, a reflexão que segue procurará tratar da inserção do pensamento em contextos específicos para os quais foram direcionados (mesmo diante da impossibilidade de recuperar-lhes qualquer sentido original).

Ainda no século XIX, Schopenhauer $(2009$, p. 61) afirmara que "o novo raramente é bom, porque o que é bom só é novo por pouco tempo". De acordo com o autor, uma obra se consolida como clássico na medida em que, sob várias óticas, recebe o reconhecimento de qualidades diferenciadas. Conforme explica, um clássico precisa apresentar:

tantas qualidades, que não é fácil encontrar alguém capaz de compreender e valorizar todas; entretanto, uma qualidade é reconhecida e valorizada por determinada pessoa, outra qualidade, por outra pessoa. Assim, no decorrer do longo curso dos séculos, em meio a interesses que variam continuamente, obtém-se afinal a cotação da obra, à medida que ela é apreciada ora num sentido, ora em outro, sem nunca se esgotar por completo (Schopenhauer, 2009, p. 68).

Esse processo não ocorre em um curto espaço de tempo, mas conforme uma historicidade que se constrói na medida em que pessoas, cada vez mais qualificadas, atribuem e reforçam qualidades inerentes ao seu conteúdo e forma. A necessidade de que não haja a simples concordância alienada por um curto espaço de tempo por diversas pessoas é fundamental para que a obra se constitua em representação histórica. É por este motivo que Calvino (1993, p. 15) infere que "é clássico aquilo que tende a relegar as atualidades à posição de barulho de fundo, mas ao mesmo tempo não pode prescindir desse barulho de fundo", de tal modo que as bases conceituais e as estruturas filosóficas e históricas fazem com que os clássicos extrapolem seu tempo histórico. Assim, obras de Santo Agostinho podem ser compreendidas até hoje por causa de sua aproximação com as concepções platônicas e com parte do pensamento renascentista, posterior ao próprio pensamento de Santo Agostinho.

A superação do tempo histórico na compreensão dos clássicos tem que ver, em certo sentido, com sua dependência em relação a outros clássicos, uma vez que seu lugar na genealogia do conhecimento se faz evidente na medida em que é compreendido em relação a outros. Nesse sentido, transita da esfera privada para a pública, transpondo limites do sigilo e da restrição do entendimento particular, sobretudo porque interessa ao coletivo "na medida em que é comum a todos nós e diferente do lugar que nos cabe dentro dele" (Arendt, 2003, p. 62).

Sob esse entendimento, tal inserção, na esfera pública, possibilita afirmar sua associação à educação do espírito, essencial para manter a unidade civilizatória transcendente ao seu tempo imediato. Dessa forma, se reproduzido como força emancipatória contrária a forças totalitárias e dogmáticas, pode se tornar história ao mesmo tempo em que a constrói como um caminho livre de preconceitos, cujas leituras possibilitam transitar no tempo e espaço como forma de universalizar conhecimentos.

A associação dos clássicos com a história possibilita, de outro modo, compreender o tempo em que a obra foi escrita; são rememorações de um tempo específico. Isto é o que ocorre com Política de Aristóteles, A República de Platão, Economia e Sociedade de Max Weber, ou com textos da literatura 
como Crime e Castigo, de Dostoievski, Metamorfose, de Franz Kafka, Diário de Anne Frank, de Anne Frank, por exemplo.

A condição de serem interpretações diferenciadas pela estrutura explicativa que apresentam é fundamental para colaborar com a construção de uma razão histórica e de compreender os fenômenos nas suas próprias épocas a partir de outro tempo histórico. Assim, o escritor do clássico é um personagem fundamental, mas não é o único. Todos os outros indivíduos que dialogam com ele, seja nos seus personagens ou comentadores, possibilitam afirmar que os clássicos são criações dos homens, em tempos que vão além da cronologia para comporem parte do tempo imaginário. Isto ocorre porque essas obras, com alguma frequência, retomam discussões essenciais para reflexões da realidade, baseadas em discussões que contrapõem as relações sociais e aspectos associados a questões morais, políticas, sociais, econômicas e ideológicas. Tratadas sob a reflexão histórica, essas questões reforçam a concepção de que os clássicos são obras centradas em discussões sobre a condição humana, independente do seu tempo histórico, cuja extrapolação de sua inserção cronológica se converte em relações entre sujeitos históricos de culturas diferentes.

Disso decorre que é na interdisciplinaridade que os clássicos ganham força. A construção de conhecimento e o seu compartilhamento entre pares de diferentes áreas das ciências humanas e sociais abrem espaço para a emersão de obras clássicas, mediante o rompimento com as classificações tradicionais das ciências em conhecimentos baseados em objetos de pesquisa. É na divergência com as estruturas de raciocínios, com as epistemologias e com os limites de onde começam e onde terminam os conhecimentos que se formam os clássicos.

Ainda, um último aspecto a ser tratado nessa relação dos clássicos e o contexto histórico diz respeito à sua inserção no conjunto de conhecimento reconhecido como fundamental para a compreensão do mundo moderno. Enquanto recursos intelectuais, auxiliam o exercício de compreensão da realidade social da vida moderna e, portanto, são, por muitos, vistos como indispensáveis. Talvez a ubiquidade de determinados pensadores do século XIX, na Sociologia, como Weber, Marx, Durkheim e Simmel, possa ser um exemplo decorrente dessa questão. Contudo arrisca-se afirmar que são clássicos não só pela sua capacidade explicativa, ou seja, pelos atributos intrínsecos de suas obras, mas também por sua referência no pensamento contemporâneo, por sua inserção privilegiada na socialização científica desse campo. Todavia isso não elimina o significativo esforço de organização do conhecimento para explicar questões até então pouco sistematizadas, caracterizando sua contribuição singular e permanência no debate intelectual. Sua análise da sociedade e do contexto em que viviam, à luz da interpretação de outros pesquisadores, na contradição ou suporte, formaram tradições de pesquisa sustentadas em seus limites e possibilidades (Alexander, 1989; Ritzer \& Smart, 2003).

Até este ponto, os clássicos foram tratados quanto às diferentes possibilidades de concepções que tomam na literatura, bem como na proposta de considerá-los uma construção social localizada no contexto histórico. Passa-se, agora, à reflexão a respeito dos clássicos na administração.

\section{Clássicos e o ensino e pesquisa em administração}

Para Schopenhauer (2009, p. 57), há três tipos de autores. Primeiro, aqueles que escrevem sem pensar, que restringem sua atividade à compilação de ideias alheias ou que fazem da sua memória a origem do próprio conhecimento, constituindo o grupo numericamente dominante. Segundo, há também os que pensam enquanto escrevem, que são capazes de sintetizar ideias e incorporar argumentos relativamente interessantes, geralmente, desenvolvendo raciocínios complexos, embora pouco originais ou inéditos. E, há um terceiro grupo, mais raro em sua composição, que engloba aqueles que pensam antes de se lançar à escrita, ou simplesmente, que escrevem apenas porque pensam.

Esse terceiro grupo é composto, comumente, daqueles que pautam por abranger autores clássicos, os quais, na perspectiva de Davis e Zald (2008), tendem a ser concebidos como exemplares de prática científica (e analítica), representando padrões alcançáveis de excelência na orientação às aspirações acadêmicas. Clássicos, nesse sentido, são "exemplos das virtudes que um trabalho científico deve possuir" (Stinchombe, 1982, p. 2), representando as manifestações concretas de princípios estéticos que 
influenciam padrões intelectuais, ou seja, o modo como se concebe o que seja um trabalho por excelência.

Stinchombe (1982) prossegue fornecendo outros elementos que justificam a leitura de clássicos, cada qual retratando uma função exercida por eles numa determinada área do conhecimento. As próximas linhas descrevem, brevemente, cada uma delas com base em Stinchombe (1982) e Thornton (2008).

Clássicos são "fonte de complexidade de pensamento" (Stinchombe, 1982, p. 2). A leitura de um clássico é uma oportunidade para forjar o desenvolvimento mental ao longo da formação acadêmica, elevando a compreensão para além de patamares descritivos e simplificados dos livros-texto.

O conhecimento dos clássicos diferencia os pesquisadores, uma vez que, numa comunidade científica, o reconhecimento público dos clássicos, em muitas circunstâncias, possibilita a comunicação de tradições de pensamento por meio da sua utilização em outras obras. Nesse sentido, antecipam expectativas e fundamentos que possivelmente serão encontrados no delineamento de outros textos. A razão subjacente para isso é seu caráter simbólico previamente discutido.

Clássicos são únicos e basilares, auxiliando, portanto, a compreensão da genealogia das ideias fundamentais num campo, conduzindo ao entendimento de proposições centrais e desdobramentos teóricos deles decorrentes.

Por serem considerados fundamentais, os clássicos auxiliam na continuidade do conhecimento e podem estimular atos imaginativos em face das ideias neles contidas (Turner, 1999). Portanto são vistos como bases frutíferas na elaboração de conjecturas iniciais (entre elas hipóteses, especulações intelectuais, etc.) acerca de aspectos que podem ser investigados na realidade empírica.

Clássicos definem a identidade intelectual de um campo do conhecimento, é por meio deles que grupos de pesquisadores dialogam e identificam-se mutuamente. Assim, o papel simbólico dos clássicos é descrito como uma função ritual pela qual uma determinada comunidade científica compartilha um senso de história comum.

Evidentemente, essa breve descrição que, em certa medida, sintetiza alguns dos pontos tratados nas seções precedentes, não representa qualquer intenção de normatização quanto às razões subjacentes à leitura dos clássicos. A discussão vista, conduzindo a esse respeito, repousa, em verdade, no reconhecimento de que o clássico é uma categoria analítica dos fundamentos de um campo, especialmente nas Ciências Sociais. Como tais, são intersubjetivamente interpretados como valorosos, justificando suas funções aos olhos de seus intérpretes. No entanto resta uma breve explanação acerca desse ponto, em especial, sobre sua inserção como parte na administração. Para isso, recorre-se à discussão exposta por Alexander (1989) sobre distinção entre os princípios empiristas das ciências naturais, em que o positivismo é a posição epistemológica predominante e a perspectiva pós-positivista da qual a explicação orientada pelos problemas empíricos faz parte, mas não a íntegra da atividade científica de construção de conhecimento. Nesse sentido, admite-se que os argumentos pós-positivistas, direcionados às ciências sociais, são igualmente válidos para a administração.

Alexander (1989) expõe essa questão como desafio à importância dos clássicos conforme imposto por visões empiristas e historicistas das ciências. Segundo seus argumentos, os clássicos, sob a ótica positivista, simplesmente, deixarão de existir por simples oposição às informações realizadas com base no empírico. Isso significa que, pela lógica positivista, o conhecimento é cumulativo, sustentado na codificação do conhecimento empírico e na formulação de teorias (para os positivistas, baseadas nas leis explicativas). Assim, por essa consideração, os clássicos, bem como sua análise rigorosa, são reduzidos a esforços meramente históricos no âmbito de determinada disciplina, uma vez que o conhecimento dos problemas do passado, em tese, seria naturalmente sobrepujado pela acumulação de conhecimento. Tal injunção contra os clássicos é também amparada pelo historicismo, na medida em que o problema da interpretação é substituído pela pesquisa histórica, isenta de pressupostos, em nome de uma razão contrária a um relativismo supostamente inerente ao debate interpretativo da prática social da ciência. Dessa forma, o historicismo destitui os clássicos, pois, segundo Alexander (1989), rompe 
implicitamente com o ciclo hermenêutico ao pressupor possível, por meio do olhar historicamente situado, compreender a intencionalidade do autor.

Nesse ponto, retorna-se à discussão realizada em outra seção acerca da construção social dos clássicos. Sua presença numa disciplina não depende meramente do empirismo, mas do consenso quanto a esquemas supracientíficos de natureza intelectual e cultural que alicerçam o discurso, especialmente na ciência social (Alexander, 1989). E disso decorre que as mesmas condições que contribuem para a relevância do discurso atuam também para destacar os clássicos. Contudo se, por um lado, estes representam um ponto de referência comum, integrando o corpo do discurso teórico, por outro, expressam contribuições singulares. Nesse sentido, a interpretação dos clássicos passa a constituir parte da discussão científica (Alexander, 1989).

Seguindo esse raciocínio, o campo da Administração, tal qual o das Ciências Sociais, é polêmico tanto para as assertivas factuais quanto para as teóricas, de tal modo que sua construção como corpo de conhecimento não é linear aos moldes do empirismo. Pode-se, então, admitir que

clássicos podem ser vistos como trabalhos exemplares de um tipo particular.... O estudo dos clássicos nos estudos organizacionais [área que pode ser considerada da administração] é o estudo da genealogia de tipos particulares de interpretações exemplares para uma gama de fenômenos e as sucessivas interações relevantes [conforme] são percebidas por acadêmicos em momentos posteriores do tempo (Davis \& Zald, 2008, pp. 639-640).

Sobre o pesquisador em particular, pode-se afirmar que seu contato com clássicos, ao longo de sua formação intelectual e científica, impacta na possibilidade de ele não se deparar com o engessamento e isolamento intelectual. Isso porque, no âmbito social, a identidade social em torno dos clássicos representa, ainda que parcialmente, a estrutura intelectual subjacente a um segmento da comunidade acadêmica e, nesse sentido, é um indicador simbólico de com quem o pesquisador anda. Por isso, retornando a Calvino (1993, p. 13), “o 'seu' clássico é aquele que não pode ser-lhe indiferente e que serve para definir a você próprio em relação e talvez em contraste com ele". Todavia modos inadequados de incorporação de ideias contidas em clássicos podem provocar rupturas estruturais, seja no âmbito de uma criação intelectual particular de um pesquisador ou na visão de mundo compartilhada por uma comunidade acadêmica.

No que concerne à Administração, sua proximidade com metodologias consideradas tradicionais de se fazer ciência (como positivismo, funcionalismo e pragmatismo), em certas situações, provoca seu afastamento dos clássicos que, aparentemente, estariam deslocados do eixo de discussão central. Por um lado, essa aparente falta de percepção quanto às particularidades inerentes aos clássicos leva ao privilégio dos aspectos metodológicos de natureza técnica das pesquisas. Por outro, a não incorporação das reflexões centradas nos clássicos, a simples negação da sua importância ou a substituição de suas narrativas clássicas por conhecimentos parcializados e restritos a resultados de pesquisas parecem ter relação com uma crise na formação autônoma na administração.

O favorecimento da incorporação de técnicas metodológicas em detrimento das bases epistemológicas e políticas que as fundamentam levam a um desenvolvimento intelectual pouco sustentável em longo prazo. Os clássicos, ao mesmo tempo em que enriquecem as discussões dos pressupostos científicos de uma determinada linha de pesquisa, são responsáveis por instigar reflexões mais aprofundadas sobre os próprios paradigmas subjacentes na construção de conhecimento na administração. Exemplo disto pode ser evidenciado nas obras de Guerreiro Ramos, Maurício Tragtenberg e Fernando Claudio Prestes Motta, que são marcadas pela originalidade, pelo ineditismo, sem, contudo, deixarem de introduzir reflexões relevantes com fundamento no diálogo entre obras contemporâneas e os clássicos da filosofia, sociologia e ciência política.

Diante do exposto, torna-se inegável a importância dos clássicos na produção de conhecimento e de reflexões na administração. Assim, como conhecimentos específicos consolidados na Psicologia e Sociologia clássica, a Administração tende a instituir-se como campo de conhecimento autônomo por meio de dinâmica similar a essas áreas, as quais tiveram clássicos a sustentarem reflexões e inquietações 
e a promoverem o interesse por novos objetos de análises. Dessa forma, os clássicos atuam como vias de interdisciplinaridade para a constituição de provocações e reflexões que levam a autonomia da área para além da incorporação de aspectos meramente metodológicos, quase sempre vinculados às ciências tradicionais.

\section{Reflexões Finais}

Iniciou-se o presente ensaio com o seguinte questionamento: por que ler os clássicos na Administração? Nessa trajetória, perpassaram-se diferentes reflexões que, sobretudo, levaram à análise do próprio significado de clássico. A proposta inicial de apresentar os porquês da leitura dos clássicos deu lugar às reflexões acerca das diferentes acepções, da natureza socialmente construída e da inserção no contexto histórico dessas obras; temas subjacentes às considerações direcionadas à área de Administração. O desenvolvimento das reflexões, aparentemente, encaminhou-se por afirmações positivas, entretanto, em decorrência da negatividade e da renúncia das afirmações dogmáticas, faz-se possível identificar e compreender os elementos que constituem compreensões a respeito dos clássicos. As conclusões e afirmações precisam ser entendidas dentro de um dos aspectos aqui tratados e que remete a uma dimensão dos próprios clássicos: a possibilidade de se refletir sobre o que se está lendo e chegar às próprias conclusões.

Destarte, não se ignoram posições que rejeitam, ou minimizam, o debate sobre os clássicos, como o empirismo de Merton, o historicismo de Skinner e algumas abordagens pós-modernas. Os efeitos negativos de clássicos também podem ser discutidos na formação paradigmática, com base em fenômenos de enclausuramento intelectual, defesa ideologizada, conservadorismo exacerbado, entre outros. No entanto defende-se a visão da ciência social de que os clássicos são parte, como discursiva. Assim, interessa conhecer a história além das ideias, mas num sentido sociológico a que contexto social e outros mecanismos estão associados, promovendo a independência do texto e sua interação com o leitor. Não se admite a objetividade das ideias, nem do ponto de vista das intenções dos autores, como passíveis de resgate a posteriori, nem como atributos determinantes para a qualificação daquilo que seria clássico, ou mesmo como conhecimento reificado, de caráter positivista. Clássicos não se definem pelo caráter factual de suas obras, mas pela sua inserção social no sistema social intelectual. Logo, são um fenômeno sociológico, seja na episteme, na forma ou nas ideias.

Dessa forma, no presente trabalho, ao questionar-se como pano de fundo sobre o que é um clássico, distancia-se de outras vertentes que compartilham dessa mesma preocupação. A primeira delas é a textualista, que considera o texto imbuído de autonomia frente ao seu contexto de surgimento e que, por isso, contém elementos atemporais, cuja apreensão se faz pela incessante leitura e releitura do texto (no caso, do clássico). A segunda é o contextualismo sociológico, que considera as ideias de um determinado texto serem compreendidas à luz da relação autor-obra-contexto social, daí derivando uma espécie de relação causal explicativa. A terceira é a do contextualismo linguístico, para o qual a compreensão verdadeira de um texto se faz pela via da compreensão da intenção do autor ao escrevê-lo. Além disso, a proposta deste ensaio repousa sobre uma possível quarta vertente, a de que um clássico é uma construção social.

Sob essa ótica, clássicos são difíceis de se definir, são taken for granted e geram muitas qualificações, configurando construções sociais e estando inseridos no contexto histórico. São a base para o cânone da disciplina, mas sem o aspecto sagrado a que a origem da palavra remete. Contudo, apesar de mudarem, apresentam-se mais perenes. São instituições e, portanto, sua essência é social, mas podem se mostrar como experiência subjetiva.

Está claro, com isso, que um clássico não decorre do vácuo social, tampouco da vontade e do querer do autor, pressupondo uma intervenção relacional humana. Entretanto ressalta-se que esse é um recorte de análise que privilegia a natureza do clássico como entidade socialmente construída. Como 
tal, a presente abordagem não teve atenção direcionada diretamente à outra questão que perpassa a presente discussão: o problema de como ler um clássico.

Diante do exposto, finaliza-se este ensaio com a elaboração de algumas indagações.

Clássicos representam um fenômeno atemporal, quando compreendido como experiência individual, caracterizando-se objetivados. Entretanto constituem-se, sobretudo, fenômenos sociais, construídos na socialização acadêmica ao longo de gerações, caracterizando-se como devires do pensamento intelectual num campo, logo, sendo legitimados e legitimando.

Clássicos não são lineares, nem resultam da cumulatividade do conhecimento, embora sua referência marque uma área de cujo debate não se escapa. Assim, não representam uma linha progressiva como Parsons (1949) tentou definir ao expor Marshall, Weber, Durkheim e Pareto como clássicos do estudo da teoria social. Contudo a não linearidade é sua qualidade, pois, por meio de reinterpretações, provocam debate acerca de suas potencialidades e limitações, dessa maneira, sustentando o discurso como um componente da prática científica.

Ainda mais, os clássicos também se mostram como fenômenos transversais, no sentido de seccionarem diferentes perspectivas, não sendo consensualmente interpretados quanto às suas características, apesar de normalmente serem reconhecidos como valorosos pelos agentes inseridos no processo de construção social do conhecimento. No entanto clássicos se apresentam igualmente como fenômenos longitudinais, construídos ao longo do tempo e passíveis de explicação sociológica, embora, normalmente, não sejam reconhecidos como tais imediatamente, mas apenas por gerações seguintes. Desse modo, a construção dos clássicos constitui uma agenda de pesquisa (Davis \& Zald, 2008).

Como os clássicos resultam da história, para que sejam reconhecidos, devem estar associados a uma postura regressiva, demonstrando que a noção de clássico não é atribuída, mas compreendida. Eles representam uma referência em tempo presente, imersos nas práticas sociais que definem uma disciplina. Como tais, são compreendidos menos como ancestrais remotos e mais como contemporâneos antigos (Skinner, 1985 como citado em Outhwaite, 2009), por vias da socialização e expressos na intersubjetividade. Assim, o célebre aforismo atribuído a Isaac Newton, "se me foi possível enxergar mais longe, foi por estar nos ombros de gigantes", deve ser lido com cuidado, uma vez que os gigantes não o são aprioristicamente, mas por decorrência do olhar sobre o passado. Como explica Porter (2005), a literatura do passado é fonte de prazeres clássicos que, lançados no presente, geram prazeres públicos carregados de história e contexto, já posicionados e citados por gerações.

Por fim, mas não finalmente, clássicos, apesar de ser uma qualificação atribuída a obras e autores, como no caso em discussão, não representam um conjunto de propriedades intrínsecas do objeto per se. Não se estabelece na forma, mas em sua essência, vista como representação social. Nesse sentido, além do caráter socialmente construído, há um componente estético associado aos clássicos, singular em sua receptividade e que os aproximam, como categoria do caráter poético em sua essência, como atitude imaginativa inerente à ciência e equivalente às artes e literatura ou outras expressões do conhecimento humano (Medawar, 2005). Nas palavras de Shelley (2001), em A Defense of Poetry:

Poetry is indeed something divine. It is at once the centre and circumference of knowledge; it is that which comprehends all science, and that to which all science must be referred.The functions of the poetical faculty are twofold: by one it creates new materials of knowledge, and power, and pleasure; by the other it engenders in the mind a desire to reproduce and arrange them according to a certain rhythm and order which may be called the beautiful and the good. (Shelley, 2001, p. 78).

Para finalizar, reitera-se que o propósito foi o de realizar um ensaio sobre o conhecimento, sem a pretensão de natureza conclusiva das ciências tradicionais ou de uma filosofia mais pragmática, enfatizando-se uma expressão em particular do conhecimento, os clássicos, que incitam muitas perguntas e incertas respostas. Contudo, e talvez por essa razão, postam-se como força motriz do conhecimento, cuja ambiguidade não está na certeza que fornecem como fundamento, mas na pluralidade inerente à sua natureza social, histórica e intelectual. 


\title{
Notas
}

\begin{abstract}
${ }^{1}$ A partir desse momento, quando for utilizada a expressão Administração o leitor deve entender que se refere ao ensino e à pesquisa em administração.

${ }^{2}$ Apesar de Ítalo Calvino abordar os clássicos na concepção da literatura, a proposta deste artigo já nasce com o pressuposto de que nas Ciências Sociais não é possível fazer a separação radical entre ciência e arte. Diferente das ciências em que os objetos de análises são mais facilmente delimitados, sobretudo por causa da possibilidade de delimitação clara do objeto de análise e por estabelecerem relações mais permanentes de interação entre o sujeito pesquisador e seu objeto de estudo.

${ }^{3} \mathrm{O}$ termo instituição utilizado neste artigo aproxima-se do proposto por Castoriadis, C. (1985). A instituição imaginária da sociedade. Rio de Janeiro: Paz e Terra.
\end{abstract}

\section{Referências}

Adorno, T. W. (1993). Minima moralia (2a ed.). São Paulo: Editora Ática.

Adorno, T. W. (2009). Dialética negativa. Rio de Janeiro: Jorge Zahar Editores.

Alexander, J. C. (1989). Sociology and discourse: on the centrality of the classics. In J. C. Alexander (Ed.), Structure and meaning (pp. 8-67). New York: Columbia University Press.

Arendt, H. (2003). A condição humana (10a ed.). Rio de Janeiro: Forense Universitária.

Benjamin, W. (1991). Walter Benjamin (2a ed.). São Paulo: Editora Ática.

Calvino, I. (1993). Por que ler os clássicos? (5a ed.). São Paulo: Companhia das Letras.

Connel, R. W. (1997). Why is classical theory classical? American Journal of Sociology, 102(6), 15111557. doi: $10.1086 / 231125$

Davis, G. F., \& Zald, M. N. (2008). Sociological classics and the canon in study of organizations. In P. S. Adler (Ed.), The Oxford handbook of sociology and organization studies: classical resources (pp. 635-646). Oxford: Oxford University Press.

Descartes (1973). Discurso do método (Coleção Os Pensadores). São Paulo: Abril Cultural.

Fromm, E. (1992). A descoberta do inconsciente social. São Paulo: Manole.

Giddens, A. (1978). As novas regras do método sociológico. Rio de Janeiro: Zahar.

Horkheimer, M. (2000). Eclipse da razão. São Paulo: Centauro.

Medawar, P. B. (2005). Os limites da ciência. São Paulo: Editora Unesp.

Meneghetti, F. K., Guarido, E. R., Filho, \& Azevêdo, A. (2012, setembro). Por que ler os clássicos nos estudos organizacionais. Anais do Encontro da Divisão de Estudos Organizacionais da ANPAD, Curitiba, PR, Brasil, 7.

Outhwaite, W. (2009). Canon formation in late $20^{\text {th }}$-century British sociology. Sociology, 43(6), 10291045. doi: $10.1177 / 0038038509345696$

Parsons, T. (1949). The structure of social action. New York: Free Press.

Porter, J. L. (2005). What is "classical" about classical antiquity? Eight propositions. Arion, 13(1), 27-61. 
Ritzer, G., \& Smart, B. (2003). Introduction: theorists, theories and theorizing. In G. Ritzer \& B. Smart (Eds.), Handbook of social theory (pp. 1-9). London: Sage.

Sartre, J. P. (1964). As palavras. São Paulo: Difusão Europeia do Livro.

Schopenhauer, A. (2009). A arte de escrever. Porto Alegre: L\&PM.

Shelley, P. B. (2001). A defense of poetry. In C. W. Eliot (Ed.), English essays: Sidney to Macaulay. (Vol. XXVII, pp. 56-88). New York: P. F. Collier \& Son.

Stinchombe, A. L. (1982). Should sociologists forget their mothers and fathers. The American Sociologist, 17(1), 2-11.

Thornton, P. H. (2008). The value of classics. In P. S. Adler (Ed.), The Oxford handbook of sociology and organization studies: classical resources (pp. 20-38). Oxford: Oxford University Press.

Turner, B. S. (1999). Classical sociology. London: Sage. 